\title{
Designing paste thickeners for copper flotation tailings, using bed depth scale-up factor \\ Majid Unesi ${ }^{1 *}$, Mohammad Noaparast ${ }^{2}$, Sied Ziaedin Shafaei², Esmaeil Jorjani ${ }^{3}$, Mahdi Yaghobi Moghaddam², Hadi Abdollahi ${ }^{2}$ \\ ${ }^{1}$ Young Researchers and Elites Club, Science and Research Branch, Islamic Azad University, \\ Tehran 1477893855, Iran; majid.unesi@gmail.com \\ ${ }^{2}$ School of Mining, College of Engineering, University of Tehran, Tehran 1439957131, Iran. \\ ${ }^{3}$ The Robert M. Buchan Department of Mining, Queen's University, Goodwin Hall, 25 Union St., Kingston, ON K7L 3N6, Canada
}

\begin{abstract}
Aim: The paste thickener could increase the water recovery and reduce the environmental impacts in tailings dam. The present work aimed to find the appropriate scale-up factor for bed depth to design paste thickener for copper tailings, using a lab glass cylinder and an operating pilot column. The thickening tests were carried out on the flotation tailing samples obtained from the Sarcheshmeh and Miduk copper mines located in Iran. Based on the industrial conditions, the values of influential parameters for paste thickener used in these experiments were $\mathrm{pH}=11$ and feed solid $=10 \%$. Flocculant type was NF43U and used as $25 \mathrm{~g} / \mathrm{t}$ with dosage of $0.25 \mathrm{~g} / \mathrm{lit}$. The unit area of Sarcheshmeh and Miduk paste thickeners were designed as 0.057 and $0.047 \mathrm{~m} 2 / \mathrm{t} / \mathrm{day}$, respectively. Based on the dry feed rates to each paste thickener as 7920 and $4320 \mathrm{t}$ /day, the thickener's diameters were determined as 23.9 and 16.1 meters which are similar to the actual thickener's diameters (24 and 16 meters), respectively. In addition to unit area, the bed depth is also important in the paste thickeners design. Hence, the ratio of industrial to lab unit bed volume for Sarcheshmeh paste thickener was obtained 75 which was equal to the ratio of industrial to lab bed depth (bed depth scale-up factor exclusively for copper flotation tailings). This procedure was validated by using the Miduk sample. The bed depth in the paste thickeners was determined as 7.5 meters, by using the bed depth scale-up factor which was comparable to the actual bed depth ( 8 meters). This research confirmed that the bed depth scale-up factor is able to correctly determine the bed depth of industrial paste thickeners for copper tailings.
\end{abstract}

Keywords: Paste thickener; bed depth scale-up factor; copper tailings; solid flux.

\section{Introduction}

The huge volumes of mineral tailings are usually discharged into tailings dam. This method necessitates the usage of large land areas. So, wind, evaporation, and seepage can affect air and underground water qualities. The paste thickeners could improve the water recovery from tailings, and contribute to decrease footprint of tailings containment structures. Determining the size of thickeners has evolved over the past 100 years ${ }^{[1]}$. There have been many researchers that have developed procedures to determine the size of thickeners. In all these methods, calculation is based on the solid flux which is identified as mass rate of solid which is processed through the thickener within a specific time period to produce a desire concentration of solid. This information is then used to determine the final thickener's diameter and size $^{[1,2]}$. In arid and semi-arid regions such as Kerman city, the scarcity of fresh water for mining industries has led to efforts towards increasing the return water and reducing environmental footprint by using paste thickener technology. There are twelve paste thickeners in Sarcheshmeh copper complex and five paste thickeners which are being operated in Miduk flotation plants. Paste thickeners can minimize the consumption of raw water and reduce the volume of tailing to disposal ${ }^{[3-4]}$. Paste is a term for the suspension solids which are relatively non-settling and non-segregating. As

\footnotetext{
Copyright (C) 2018 Majid Unesi et al.

doi: $10.18063 / \mathrm{nn} . \mathrm{v} 2 \mathrm{i} 1.378$

This is an open-access article distributed under the terms of the Creative Commons Attribution Unported License

(http://creativecommons.org/licenses/by-nc/4.0/), which permits unrestricted use, distribution, and reproduction in any medium, provided the original work is properly cited.
} 
the name implies paste has a self-supporting structure and when deposits on the ground, it forms a slope with different inclination depending on the solids concentration. Paste properties are produced by the relatively high suspended solids concentrations $^{[5]}$. Applications such as paste backfill are all examples for potential application of paste thickening method in the mining industries ${ }^{[6]}$. The principal of paste thickeners is that the compression zone is much deeper than other thickening equipment such as high rate and high compression units. As the compression zone gets deeper, the underflow density and water recovery for a given flux rate increase as a result of two factors: Longer bed settling time and the net weight of the bed. Aggregates settle at the bottom of thickener and consequently create a compressive force which is resulted to expel interstitial water from aggregate's bed. This force increases with depth ${ }^{[7]}$.

The various methods use small samples in batch scale to simulate and predict performance of large commercial projects. The variability in particle size, chemical composition, and nature of the representative samples lead to non-ideal conditions in mineral processing. Therefore equipment manufacturers and design groups have typically applied scale-up factors to design the industrial process' and equipment ${ }^{[8]}$. Normally, paste thickeners are operated in non-ideal conditions. So, the development of a scale-up methodology is necessary for planning the industrial thickening operation and earlier equipment sizing which are usually based on the batch sedimentation tests. The usage of scale-up factor is required because the knowledge and measurement technologies are still insufficient for a reliable prediction of the paste thickener's performance from laboratory tests ${ }^{[9]}$. The basic thickening theories and procedures to design the thickeners have been presented by researches ${ }^{[10-17]}$. Moreover, numerous models were used to determine the solids volume fraction, the compressive yield stress and the hindered settling function to predict the thickener performance ${ }^{[18-22]}$. Then, some others developed software for simulation of thickening with some assumptions based on the fundamental suspension properties ${ }^{[23-25]}$. These models and algorithms were accurate at the specific conditions and accuracy was reduced at other conditions ${ }^{[26-28]}$. The recent mathematical, numerical and phenomenological analyses of thickening models have been employed to predict and simulate the suspension settling characteristics ${ }^{[29-33]}$. In all the above-cited works, the scientists have tried to find the best model to provide the basis for realistic thickener simulators.

Designing the paste thickeners consist the unit area and bed depth determination. The unit area is determined by known thickening theories and models. In this paper, the determination of bed depth of paste thickener was investigated by scale-up factor. The thickener scale-up is complex because the mineral characteristics, tank geometry and operating conditions are different in batch and plant operations. The scale-up factor for prediction of thickener dimension is generally derived by comparison of industrial thickeners and laboratory batch column performance. On the other hand, the main emphasis of this paper lies in the paste thickener bed depth scale-up for copper tailings by using the laboratory and pilot plant experiments on the Sarcheshmeh tailing sample. Besides, the Miduk tailing sample was also used to validate the scale-up procedure.

\section{Materials and Methods}

Tailing samples from Sarcheshmeh and Miduk copper flotation plants were used in all thickening experiments. Size distribution of the representative samples were then determined by a combination of sieving and cyclosizer methods which are shown in Figure 1. Also, XRD analysis of the samples is presented in Table 1. Furthermore, solid density (SG) was determined using a pycnometer which presented the skeletal solid density of the particles. The density of Sarcheshmeh and Miduk tailing samples were obtained 2.8 and $2.75 \mathrm{t} / \mathrm{m} 3$, respectively. 


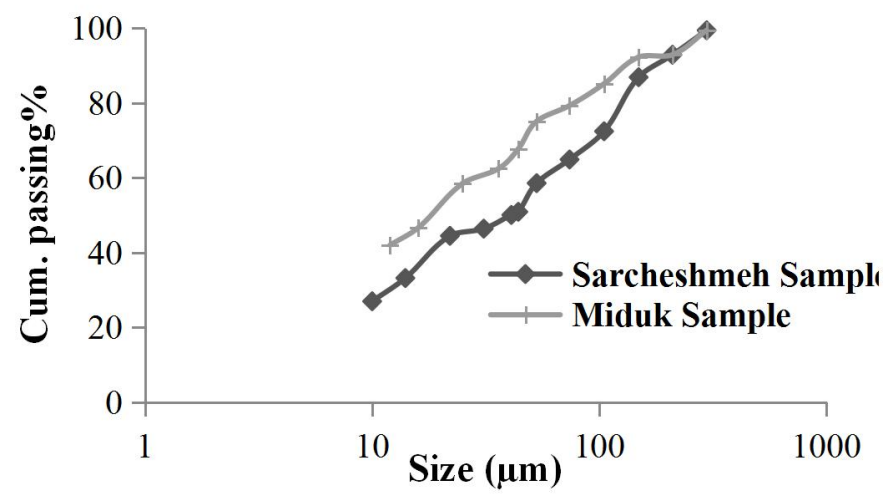

Figure 1; Particle size distribution of tailing samples in two copper flotation plants.

\begin{tabular}{|l|l|l|}
\hline Minerals & Sarcheshmeh sample & Miduk sample \\
\hline $\begin{array}{l}\text { Aluminum Silicate (Clinochlore, Illite, } \\
\text { Chamosite, Anorthite) (\%) }\end{array}$ & 75.5 & 71 \\
\hline Quartz (\%) & 22 & 25.2 \\
\hline Pyrite (\%) & 2.4 & 3.3 \\
\hline Total (\%) & 99.9 & 99.5 \\
\hline
\end{tabular}

Table 1. XRD analysis of tailing samples.

In order to study the behavior of tailings in the thickening process, the samples were taken as a suspension and then treated by tailings wastewater to run various experiments with the plant condition. The sample was diluted to solid concentration of $10 \%$ and $\mathrm{pH}$ of solution was adjusted to 11 , based on the industrial condition. To find the bed depth scale up factor, the data of lab, pilot and industrial scales should be compared with each other. Thus, dewatering is measured under conditions more representative of industrial scale thickening. A high molecular weight anionic polyacrylamide (NF43U from SNF Co.) was used to flocculate the suspended materials. The concentration of used flocculant was $0.25 \mathrm{~g} /$ lit and hydrated for 1 hour before experiment. The dosage of flocculant in the Sarcheshmeh and Miduk paste thickeners is usually between 20 and $30 \mathrm{~g} / \mathrm{t}$. So, the thickening tests were carried out with $25 \mathrm{~g} / \mathrm{t}$.

In this work, the Wilhelm-Naide method was used in order to determine the thickener unit area. In mid-1970's the technical department of Environ-tech Corporation evaluated and developed a method to use the laboratory data for the determination of thickener's size. By this approach, performing the multiple analyses of the data and the issues of under or over sizing associated with the Kynch method are not necessary and could be eliminated. This procedure is based on the same principles that Coe-Clevenger and Kynch used. The primary difference is that the velocity calculations were extended over the entire settling curve. The tangent lines to the curve intersect the vertical axis and the solid concentration is defined. The results provide a method that includes the free settling zone, the hindered settling zone and the compression zone affect within a single method. The velocity and concentration data are plotted as a log-log scale. The data represents a number of line segments to determine the coefficients of "a" and "b" in equation 1 [34]:

$$
V=a C^{-b}
$$

Where, $\mathrm{V}$ and $\mathrm{C}$ are the settling rate (m/day) and solid concentration ( $\mathrm{t} / \mathrm{m} 3)$ respectively. Also "a" and " $\mathrm{b}$ " are the constant coefficients. The values determined for "a" and "b" are then used to determine the thickener's unit area using equation 2:

$$
U A=\left[\frac{\left(\frac{b-1}{b}\right)^{b-1}}{a b}\right] C_{u}^{b-1}
$$

Where, $\mathrm{Cu}$ is the underflow solid concentration $(\mathrm{t} / \mathrm{m} 3)$. The unit area determined by the Wilhelm and Naide approach is multiplied by a factor equal to $(\mathrm{h} / \mathrm{H}) \mathrm{n}$, where "h" is the average depth of pulp in the cylinder, "H" is usually 
taken as 1 meter, and " $n$ " is the exponent obtained from the standard curve. For conservative design purposes, the minimum value of this factor that should be used is 0.25 . The equation is presented as follows [34]:

$$
U A_{\text {corrected }}=\left(\frac{h}{H}\right)^{n} \times U A_{\text {calculated }}
$$

The bed depth is the important factor for designing the paste thickeners. Also, the correction factor of unit area in Wilhelm and Naide method is a function of bed depth. So, this method is usually used for paste thickener design by manufacturers.

In this study, settling tests were performed in a 5 liter clear scaled glass cylinder (height $\times$ diameter $=$ $1.09 \mathrm{~m} \times 0.076 \mathrm{~m})$. It was filled with specific weights of sample and water. In these tests, flocculant was added in predetermined times. Mixing with convenient rotation speed is so important, because it provides an environment with sufficient contacts of particles and flocculant molecules. But excessive mixing rate breaks long flocculant molecules. On the other hand, mixing with low rotation speed may also lead to non-homogenous distribution of flocculant on the solid particles. The slurry was mixed by 3 times inversion (turning the graduated cylinder upside down). Also, the height of bed line was recorded against time.

A plexiglass column was used in pilot plant experiments with $4 \mathrm{~m}$ height and $0.2 \mathrm{~m}$ internal diameter. A narrow diameter was chosen so that the macroscopic flow effects are not significant when the vessel diameter is less than $0.3 \mathrm{~m}$ [35]. Therefore, the channeling and re-circulation were not expected. Thus, this simplification allowing trends in behavior to be understood, however, exact predictions may not necessarily be possible and it could be hidden in bed depth scale up factor.

A schematic set-up column for pilot plant thickening process is demonstrated in Figure 2. The suspended solid (sample and water) and flocculant were delivered to the column at a height of approximately $3 \mathrm{~m}$ via a feed-well by peristaltic pump. Overflow was then collected by a peripheral launder. In this column, the interface between the feed and clarified water could be observed. Based on the experimental conditions, the suspension was transferred to the pilot plat column and shortly after the column was filled, three zones were distinguishably formed. The top of the column was characterized by a clarified zone. In the middle zone, individual aggregates were observed which were settling and the lower zone was an opaque region in which the solids settled. There was a marked interface between the middle and lower zones that is referred to herein as the "bed height" or "bed depth."

A series of continuous experiments were performed on the flotation tailings by pilot plant column. The bed height was allowed to increase to approximately $80 \%$ of the target height, at which point the underflow pump was turned on. This was done to compensate the slow dynamical response in the column. In practice, the underflow pump speed needed to be periodically adjusted to keep the bed height constant due to variation in underflow solid content. Therefore, the underflow rate varied with the changing the underflow pump speed to control the bed height. In all experiments, the bed height was fixed as predetermined level with $10 \%$ as standard deviation. At start time of each run, the average rate of underflow increased, which corresponds to a decrease in solid concentration of underflow as the system moved to the steady state. Furthermore, the underflow solid content was initially unsteady and after a while, this fluctuation disappeared and consequently, the underflow solid content remained fairly constant. For each run, the column was operated for sufficient time to achieve the steady state prior to sampling procedure. On this basis, the steady-state condition would take from 2 to $5 \mathrm{~h}$, depending on the bed height. After this time, samples from column underflow were collected at 15-min intervals. No solid particle was observed in the overflow for each condition of experiment, and its solution (water) was clear.

\section{Results and Discussion}

The batch sedimentation experiments were performed using Sarcheshmeh and Miduk tailing samples (Figure 3). The Wilhelm-Naide method was used to determine the required unit area of the thickeners. According to the test-work data, the "a" and "b" values are extracted by the following equations:

For Sarcheshmeh: $\mathrm{V}=0.0109 \times \mathrm{C}^{-8.025}$ 
For Miduk: $\quad \mathrm{V}=0.0057 \times \mathrm{C}^{-8.644}$

It can be seen that the " $a$ " and " $b$ " values for Sarcheshmeh sample are 0.0109 and 8.025 and for Miduk sample are 0.0057 and 8.644, respectively. The results are presented in Tables 2 and 3.

\begin{tabular}{|c|c|c|c|c|c|c|}
\hline $\begin{array}{l}\text { Solid } \\
\text { content \% }\end{array}$ & $\begin{array}{l}\text { Bed } \\
\text { height } \\
\text { (m) } \\
\end{array}$ & $\begin{array}{l}\text { Concentration } \\
(\mathrm{t} / \mathrm{m} 3)\end{array}$ & UA (m2/t/day) & $\begin{array}{l}n \\
\text { coefficient }\end{array}$ & $\begin{array}{l}\text { Height } \\
\text { correction } \\
\text { exponent }\end{array}$ & $\begin{array}{l}\text { Corrected UA } \\
(\mathrm{m} 2 / \mathrm{t} / \text { day })\end{array}$ \\
\hline 58.48 & 0.0932 & 0.9205 & 2.5085 & 0.014001 & 0.9673 & 2.427 \\
\hline 58 & 0.0944 & 0.9087 & 2.2902 & 0.014262 & 0.9669 & 2.214 \\
\hline 57 & 0.0970 & 0.8844 & 1.8930 & 0.014824 & 0.9660 & 1.829 \\
\hline 56 & 0.0997 & 0.8605 & 1.5624 & 0.015415 & 0.9651 & 1.508 \\
\hline 55 & 0.1024 & 0.8371 & 1.2874 & 0.016038 & 0.9641 & 1.241 \\
\hline 54 & 0.1053 & 0.8142 & 1.0590 & 0.016693 & 0.9631 & 1.020 \\
\hline 53 & 0.1083 & 0.7917 & 0.8696 & 0.017385 & 0.9621 & 0.837 \\
\hline 52 & 0.1114 & 0.7696 & 0.7127 & 0.018115 & 0.9610 & 0.685 \\
\hline 51 & 0.1147 & 0.7479 & 0.5830 & 0.018887 & 0.9599 & 0.560 \\
\hline 50 & 0.1180 & 0.7265 & 0.4758 & 0.019704 & 0.9588 & 0.456 \\
\hline 49 & 0.1215 & 0.7056 & 0.3875 & 0.020569 & 0.9576 & 0.371 \\
\hline 48 & 0.1252 & 0.6851 & 0.3149 & 0.021488 & 0.9563 & 0.301 \\
\hline 47 & 0.1290 & 0.6649 & 0.2552 & 0.022464 & 0.9550 & 0.244 \\
\hline 46 & 0.1330 & 0.6450 & 0.2063 & 0.023502 & 0.9537 & 0.197 \\
\hline 45 & 0.1371 & 0.6255 & 0.1663 & 0.024609 & 0.9523 & 0.158 \\
\hline 44 & 0.1414 & 0.6064 & 0.1336 & 0.02579 & 0.9508 & 0.127 \\
\hline 43 & 0.1460 & 0.5876 & 0.1071 & 0.029252 & 0.9453 & 0.101 \\
\hline 42 & 0.1507 & 0.5690 & 0.0855 & 0.031894 & 0.9414 & 0.080 \\
\hline 41 & 0.1557 & 0.5508 & 0.0680 & 0.034783 & 0.9374 & 0.064 \\
\hline 40 & 0.1609 & 0.5329 & 0.0540 & 0.036601 & 0.9353 & 0.050 \\
\hline
\end{tabular}

Table 2- The Sarcheshmeh paste thickeners unit area (UA), by Wilhelm-Naide method.

\begin{tabular}{|l|l|l|l|l|l|l|}
\hline $\begin{array}{l}\text { Solid } \\
\text { content \% }\end{array}$ & $\begin{array}{l}\text { Bed } \\
\text { height } \\
(\mathbf{m})\end{array}$ & $\begin{array}{l}\text { Concentration } \\
\mathbf{( t / m 3 )}\end{array}$ & UA (m2/t/day) & $\begin{array}{l}\mathbf{n} \\
\text { coefficient }\end{array}$ & $\begin{array}{l}\text { Height } \\
\text { correction } \\
\text { exponent }\end{array}$ & $\begin{array}{l}\text { Corrected } \\
\text { (m2/t/day) }\end{array}$ \\
\hline 56.58 & 0.0981 & 0.8742 & 2.838 & 0.015136 & 0.9655 & 2.74 \\
\hline 56 & 0.0997 & 0.8605 & 2.5152 & 0.015415 & 0.9651 & 2.427 \\
\hline 55 & 0.1024 & 0.8371 & 2.0375 & 0.016038 & 0.9641 & 1.964 \\
\hline 54 & 0.1053 & 0.8142 & 1.6475 & 0.016693 & 0.9631 & 1.587 \\
\hline 53 & 0.1083 & 0.7917 & 1.3295 & 0.017385 & 0.9621 & 1.279 \\
\hline 52 & 0.1114 & 0.7696 & 1.0707 & 0.018115 & 0.9610 & 1.029 \\
\hline 51 & 0.1147 & 0.7479 & 0.8604 & 0.018887 & 0.9599 & 0.826 \\
\hline 50 & 0.1180 & 0.7265 & 0.6899 & 0.019704 & 0.9588 & 0.661 \\
\hline 49 & 0.1215 & 0.7056 & 0.5518 & 0.020569 & 0.9576 & 0.528 \\
\hline 48 & 0.1252 & 0.6851 & 0.4402 & 0.021488 & 0.9563 & 0.421 \\
\hline 47 & 0.1290 & 0.6649 & 0.3502 & 0.022464 & 0.9550 & 0.334 \\
\hline 46 & 0.1330 & 0.6450 & 0.2778 & 0.023502 & 0.9537 & 0.265 \\
\hline 45 & 0.1371 & 0.6255 & 0.2197 & 0.024609 & 0.9523 & 0.209 \\
\hline 44 & 0.1414 & 0.6064 & 0.1732 & 0.02579 & 0.9508 & 0.165 \\
\hline
\end{tabular}




\begin{tabular}{|l|l|l|l|l|l|l|}
\hline 43 & 0.1460 & 0.5876 & 0.1361 & 0.028144 & 0.9473 & 0.129 \\
\hline 42 & 0.1507 & 0.5690 & 0.1066 & 0.030714 & 0.9435 & 0.101 \\
\hline 41 & 0.1557 & 0.5508 & 0.0831 & 0.033524 & 0.9396 & 0.078 \\
\hline 40 & 0.1609 & 0.5329 & 0.0646 & 0.036601 & 0.9353 & 0.060 \\
\hline 39 & 0.1664 & 0.5153 & 0.0499 & 0.039978 & 0.9308 & 0.046 \\
\hline 38 & 0.1722 & 0.4980 & 0.0385 & 0.043689 & 0.9260 & 0.036 \\
\hline
\end{tabular}

Table 3. The Miduk paste thickeners unit area (UA), by Wilhelm-Naide method.

With increasing the solid concentration in the sedimentation tests, the settling condition was changed from free to hindered settling, transition settling and then compression zone (Figure 4). Depending on the test condition, the contributions of free, hindered, transition settling and compression zone can be different. Free sedimentation has the fastest settling rate as aggregates can settle freely without interference. Then, hindered settling is occurred as aggregates start to form self-supporting network structures with some lateral bridging which hinders the settling rate. A denser self-supporting network is formed in transition settling zone, but the sediment is not yet fully compacted. In the compression zone, the sediment is fully compacted and water is locked in the structures between particles. A point at which the transition settling ends and compression zone starts is referred to compression, critical or gel point. On the other hand, the solid content at which the suspension forms a network structure is define as gel point and at the steady state, solids concentration at the top of bed is equal to the gel point. Below the gel point, the suspension is not networked [24, 29, 33, and 34]. Determining the gel point is essential in some of thickener's sizing methods such as Wilhelm-Naide. During the settling test, as time goes on and changing the condition from free to hindered settling, sedimentation rate decreases non-linearly. Therefore, gel point can be located where the acceleration of the interface displacement approaches to zero.

As discussed above, at each of these transitions, there is a discontinuity in the sedimentation curve. The discontinuity of gel point in the settling curve is not always readily discernable and some procedures have been suggested to try and locate the compression point on the settling curve. The Mondal and Majumdar method as one of these procedures is used to find the gel point in this work. In this method, the mud-line height at the gel point can be obtained from a plot of $\mathrm{dH} / \mathrm{dt}$ versus time. Then, the change in slope at the gel point could be evident ${ }^{[36]}$. In practice, the gel points of the Sarcheshmeh and Miduk samples were obtained 40\%-41\% and 38\%-40\%, respectively (Figure 4). Therefore, the unit area for the Sarcheshmeh and Miduk paste thickeners were obtained 0.057 and $0.047 \mathrm{~m} 2 / \mathrm{t} / \mathrm{day}$. Since the feed rate (dry solid) of each thickener for the Sarcheshmeh and Miduk paste thickeners were 7920 and 4320 t/day, so the thickeners' diameters were determined as 23.9 and 16.1 meters which were consistent with the actual thickeners' diameters (24 and 16 meters), respectively.

The pilot plant experiments were carried out using the tailing sample prepared from the Sarcheshmeh copper mine. Several column experiments were performed at different solid fluxes (10, 14.3, 20 and 28.3 ton/m2/day) and bed heights $(0.5,1,1.5,2$ and 2.5 meters). The results of experiments in different solid fluxes and bed depths are shown in Figure 5. It can be seen that the bed depth had a significant effect on the underflow concentration. The bed consolidation was controlled by the compressibility and permeability of the bed which was indicated by the underflow solid concentration. The compressibility and permeability of a suspension is characterized by the compressive yield stress and hindered settling, respectively. The compressive yield stress is the strength of the aggregate network to resist consolidation and formation of bed with higher solid content. The aggregates pressure on the top and bottom of the bed is low and high, respectively. So, there is little mass of aggregates above the top part of the bed, while the bottom part of the bed supports a greater mass of aggregates. Permeability of the congregated particles decreases as the aggregate consolidates and blocks paths of network water, which significantly slows down the rate of further water removal. The mass pressure causes the aggregates' network to consolidate and formation of the thickening product with higher solid content such as paste occurs. The clay minerals are included a significant proportion of the sample (Table 1). These minerals are able to absorb water into their internal structure that is not available for recycling, and increase the 
apparent volume of discharged material to the tailings dam. The high surface area-to-volume ratios of clays suggest the existence of nano-scale capillaries capable of storing large quantities of water. Furthermore, as the solid flux is decreased, the underflow solid concentration increases and at a certain concentration, the particles are affected by hydraulic and solid forces which the solid forces are arisen between the particles in higher depth. Thus the necessary depth in compression zone is needed to compress the aggregates. According to Figure 5, the optimum solid flux and bed depth could result the desired solid concentration of underflow. The solid flux reduction from 28.5 to $10 \mathrm{t} / \mathrm{m} 2 /$ day caused an increase in the underflow solid concentration from $51.2 \%$ to $55.8 \%$ at $2.5 \mathrm{~m}$ column height. In the compression zone, with an increasing the solid concentration towards the bottom of the column, the particles are affected partly by hydraulic forces and partly by solid forces. This impact was increased by decreasing the solid flux to $14.3 \mathrm{t} / \mathrm{m} 2 /$ day. Further decreases in the solid flux did not have a significant effect on the underflow solid concentration. Moreover, it was concluded that if solid flux is maintained at high rate, there would be insufficient detention time for settling and consolidation. But if it is too low, solid depth increased the settling performance by causing consolidation of the lower part layers. It should be noted that the convenient rate of solid withdrawal from thickener's underflow should be maintained to produce a smooth and continuous flow. Otherwise, turbulence condition and other anomalies may occur.

As shown in Figure 5, the underflow solid content at 10 and $14.3 \mathrm{t} / \mathrm{m} 2 /$ day solid fluxes for $2.5 \mathrm{~m}$ column height was about $55.5 \%$, whereas it was measured as $42 \%, 44.4 \%, 46.8 \%$ and $49 \%$ for $0.5,1,1.5$ and $2 \mathrm{~m}$ heights, respectively. It could be concluded that decreasing the solid flux until the specific point impacted on the underflow solid content and bed depth, but this impact was limited, and further reduction in the solid flux had no meaningful effect. Similar results were observed for all bed depths. On the other hand, operating the thickener at the maximum feed rate is not advisable, since a small change in aggregate properties, i.e. as caused by a temporary reduction in flocculent activity, or dose, could lead to lower settling rates and solid overflow. Furthermore, low residence times limit the opportunity for compressive dewatering and consequently underflow densities do not greatly exceed the material gel point. Also, the deep beds provide for high compressive stresses; while the typically low solid fluxes mean that residence times are relatively high. For paste thickeners in which the compression forces are the restricting factors, the capacity is influenced by the available height of the compaction zone as well as the area, whereas the capacity of other types of thickeners is not influenced by the height, but it is only area dependent.

As mentioned above, a high underflow density is related to the compressibility of the material. Thus, the bed depth as a main parameter of compression should be determined in paste thickener design. In this paper, it is determined in lab, pilot and industrial scales for Sarcheshmeh Copper tailing to find out the bed depth scale up factor. Then the Miduk copper tailing is used for validation.

The log-log scale plot of unit bed volume versus average pulp depth usually produces a straight line. By decreasing the slope of this line, underflow solid concentration increases. The bed depth scale-up factor was obtained by drawing this plot for Sarcheshmeh tailing sample. As illustrated in Figure 6, the straight line was produced by three points related to laboratory, pilot and Sarcheshmeh industrial scales data. The derived formula for this line is presented as follows:

$$
\text { unit mud volume }=0.057 \times \text { bed height }
$$

Considering the bed depths as 0.0932, 2.5 and 7 meters in the laboratory (Figure 3), pilot (Figure 5) and industrial scales for Sarcheshmeh sample, the unit bed volumes were obtained as $0.0053,0.1427$ and $0.399 \mathrm{~m} 3 / \mathrm{t} /$ day, respectively. Hence, the bed depth scale-up factor for the unit bed volume obtained from ratio of lab to industrial or pilot to industrial scales data which were 75 and 2.8, respectively. This proportion was also valid for bed depth.

$$
\frac{\left(\text { unit mud volume }_{\text {ind.scale }}\right.}{(\text { unit mud volume })_{\text {lab.scale }}}=\frac{\text { bed depth }}{\text { ind.scale }}=\frac{0.399}{\text { bed depth } \text { lab.scale }_{\text {f }}}=\frac{7}{0.0053}=75
$$

Based on the feed rate to each paste thickener in the Sarcheshmeh copper mine as $7920 \mathrm{t} / \mathrm{day}$, the bed volume was 
obtained $3160 \mathrm{~m} 3$. In the case of Miduk tailing sample, considering the bed depth as 0.0981 meter in laboratory scale, the unit bed volume was obtained $0.0046 \mathrm{~m} 3 / \mathrm{t} /$ day. Regarding to the bed depth scale-up factor as 75 , the unit bed volume in industrial scale was obtained $0.3463 \mathrm{~m} 3 / \mathrm{t} /$ day. Also, by considering the feed rate of each paste thickener in the Miduk copper mine as $4320 \mathrm{t}$ /day, the bed volume and depth were obtained $1500 \mathrm{~m} 3$ and 7.5 meters, respectively. Finally, by comparing the determined and actual bed depths for Miduk paste thickeners (7.5 and 8 meters, respectively), it is concluded that it was established a good approximation between this parameter. Therefore, this bed depth scale up factor can be used to determine the bed depth of industrial paste thickeners for copper flotation tailings.

DILUTION WATER

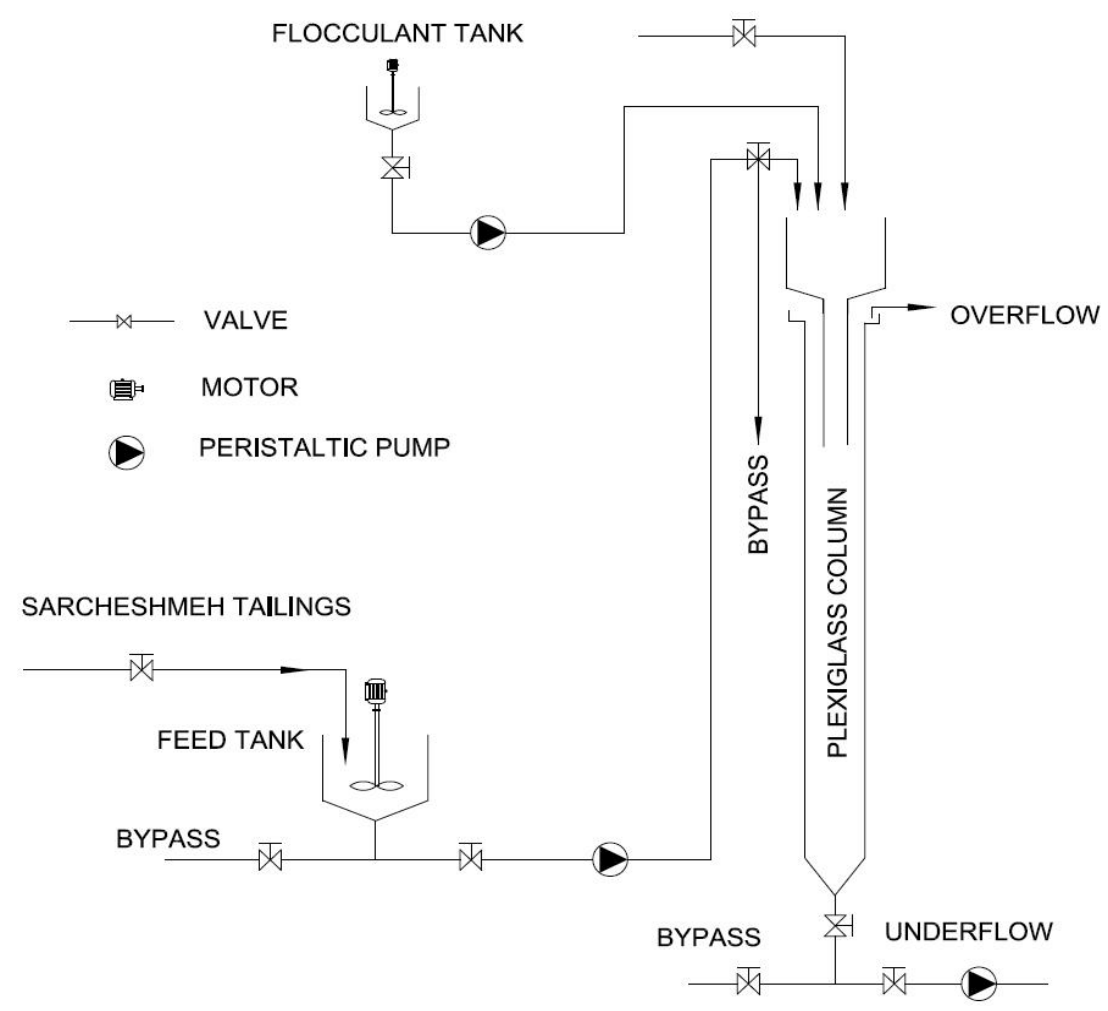

Figure 2; Schematic thickening process with the pilot plant column.
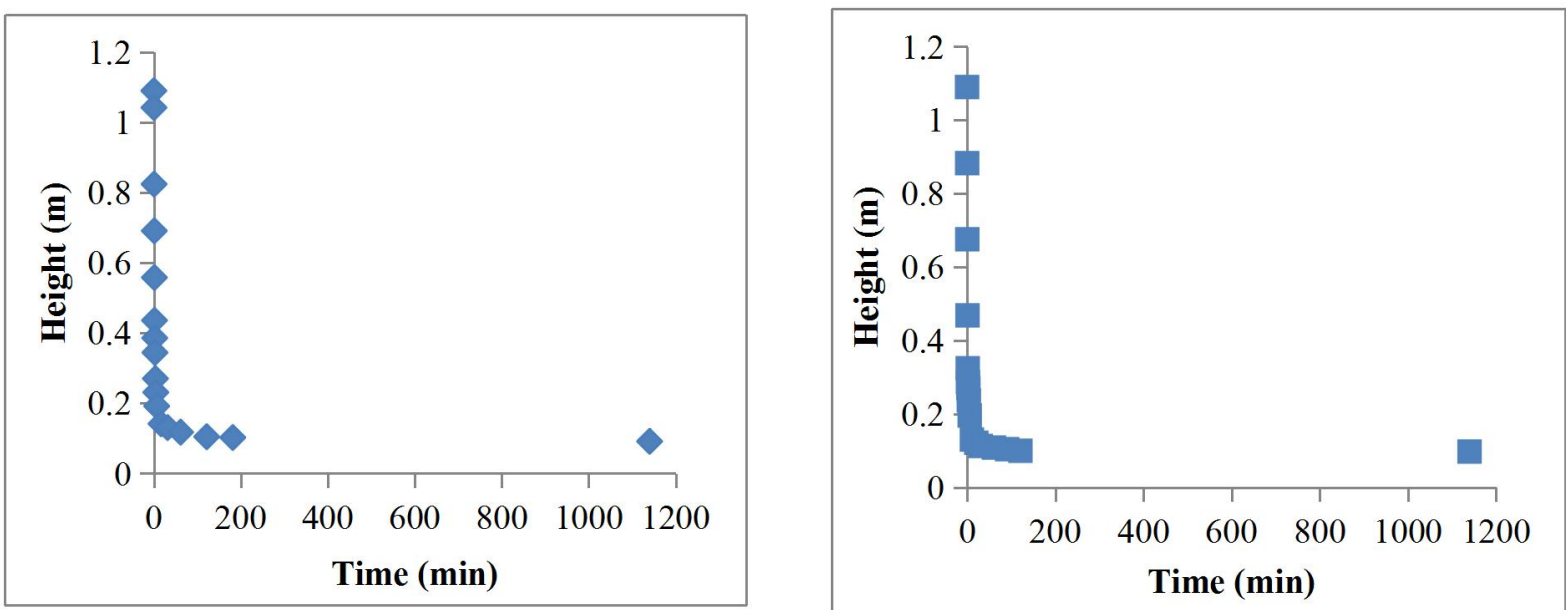

Figure 3; Sedimentation curves for Sarcheshmeh and Miduk samples. 

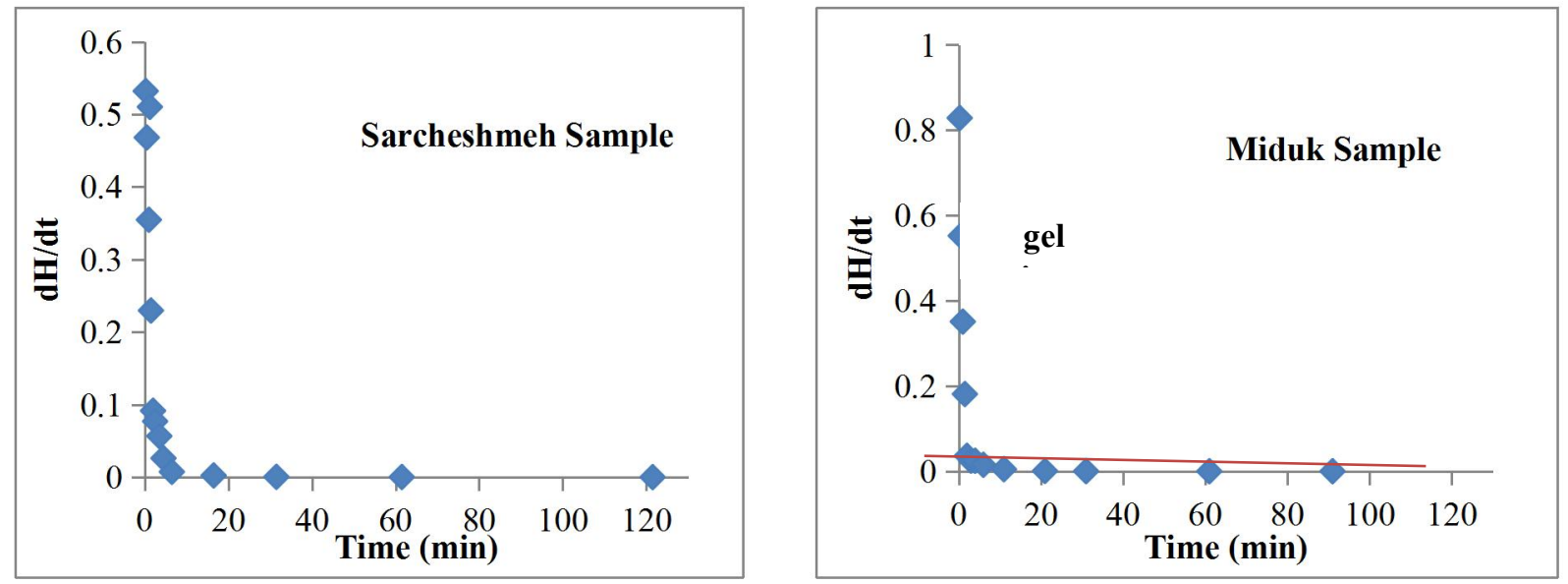

Figure 4; Plots of changing in slope versus time for Sarcheshmeh and Miduk Samples to find gel point.

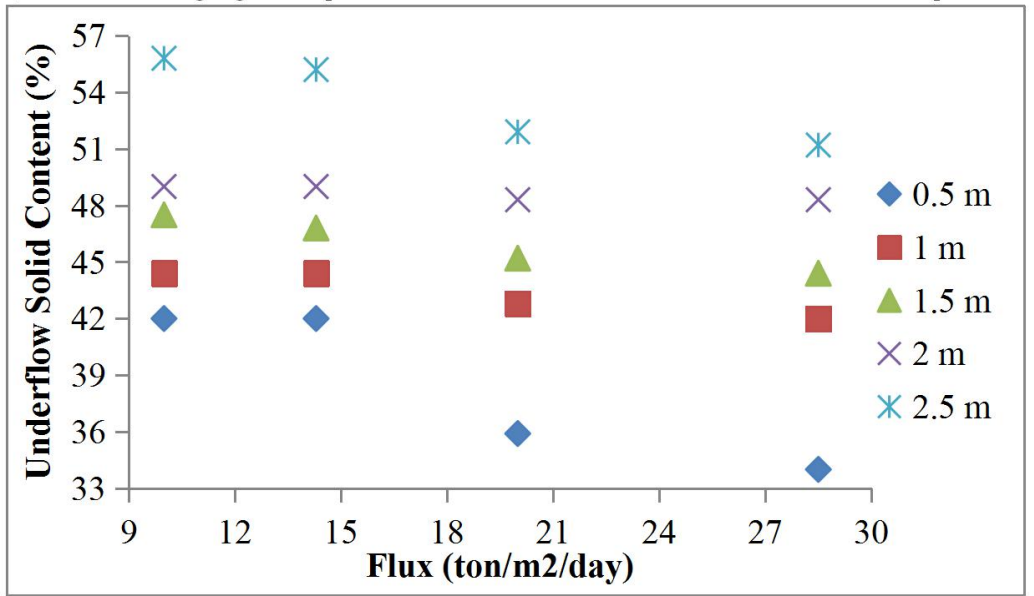

Figure 5; The relationship between fluxes, bed levels and underflow solid percent in the pilot plant column experiments.

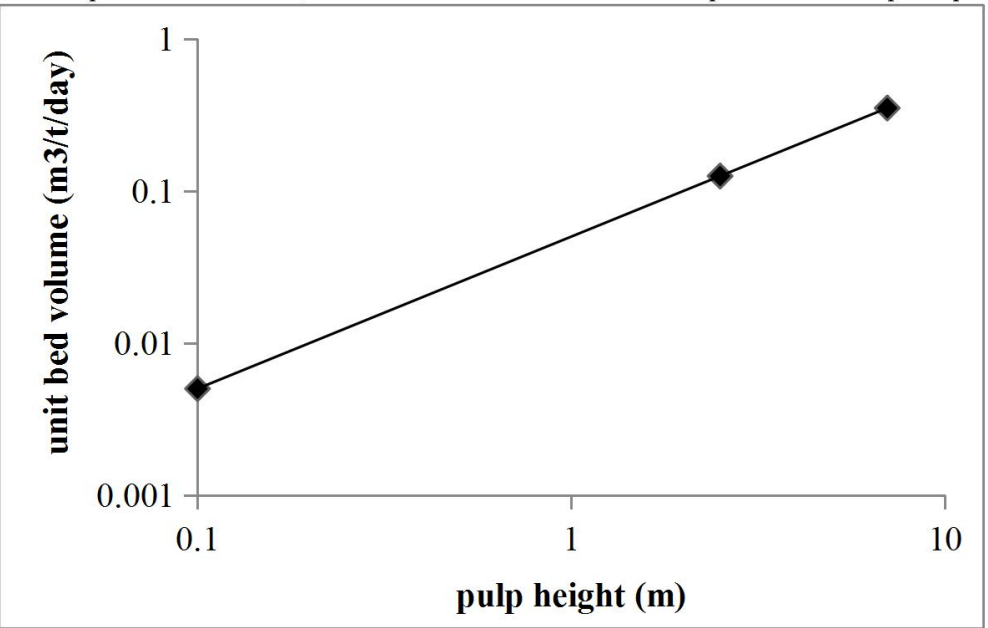

Figure 6; The unit bed volume versus pulp depth for Sarcheshmeh tailing sample.

\section{Conclusion}

The scarcity of fresh water for mining industries has led to efforts towards increasing the return water and reducing environmental footprint by using paste thickener technology. So, the appropriate design of paste thickener could increase the water recovery and reduce the environmental impacts. A standard comparison between laboratory batch sedimentation tests and industrial paste thickener performance, based on the unit bed volume, was developed and evaluated in order to estimate the bed depth scale-up factors. The results showed that there was a good consistency to scale-up the bed depth of paste thickener design from batch tests. The unit area of Sarcheshmeh and Miduk paste 
thickeners were determined as 0.057 and $0.047 \mathrm{~m} 2 / \mathrm{t} /$ day. Based on the dry feed rates for each thickener in the Sarcheshmeh and Miduk paste thickeners as 7920 and 4320 t/day, the thickener's diameters were determined as 23.9 and 16.1 meters respectively, which were consistent with the actual thickeners' diameters (24 and 16 meters). The pilot plant tests showed that by decreasing the solid flux until the specific point impacted on the underflow solid content and bed depth, but this impact was limited, and further reduction in the solid flux had no meaningful effect. So, this parameter was considered as 10 and $14.3 \mathrm{t} / \mathrm{m} 2 /$ day in the tests, respectively. The underflow solid content for both solid fluxes at $2.5 \mathrm{~m}$ column height was about $55.5 \%$. The ratio of industrial to lab unit bed volume in the Sarcheshmeh paste thickeners was obtained 75 which was equal to the ratio of industrial to lab bed depth (bed depth scale-up factor exclusively for copper flotation tailings). Furthermore, the ratio of industrial to pilot plant unit bed volume was obtained 2.8. The lab tests on the Miduk flotation tailing sample validated the scale-up procedure. As a final result, the bed depth in the Miduk paste thickeners was scaled up and determined as 7.5 meters which was comparable to the actual bed depth (8 meters).

\section{Acknowledgment}

This work was supported by the Integrated Water Master Plan (IWMP) of National Iranian Copper Industry Co (NICICO). We are grateful to Mr. H. Seif (Head of IWMP), and Mr. A. Zarabadipour (Head of Mineral processing) for facilities, scientific and technical assistance. We also thank all members of the project team for their contributions to the work reported in this paper

\section{References}

1. Jewell R, Fourie A. Paste and Thickened Tailings-A Guide Australia Centre for Geomechanics, Perth, Western Australia 2006; 6.

2. Slottee J, Johnson J. Paste thickener design and operation selected to achieve downstream requirements 2009; 69-76.

3. Sofra F, Boger D. Slope Prediction for thickened tailings and paste, tailings and mine waste, Rotterdam 2001; 75-83.

4. Newman P, Landriault D. The use of paste technology in the surface disposal of mineral waste, Birmingham 1997; 55.

5. Arbuthnot I, Garrway B, Triglavcanin R, et al. Designing for paste thickening, Perth, Australia $2005 ; 597$.

6. Meggyes T, Debreczeni A. Paste technology for tailings management. Land Contamination \& Reclamation 2006; $14 ; 815-27$.

7. Unesi M, Noaparast M, Shafaei SZ, et al. The Effects of Ore Properties on the Characterization of Suspension in Settling and Compression. International Journal of Mining \& Geo-Engineering 2014; 48: 101-14.

8. Zlokarnik M. Scale-up in chemical engineering, Germany, John Wiley \& Sons 2006.

9. Tarleton S, Wakman R. Solid/liquid separation: scale-up of industrial equipment, Elsevier 2011

10. Coe H, Clevenger G. Methods for determining the capacities of slime thickening tanks. Transaction AIME 1916; 55: 356.

11. Kynch GJ. A theory of sedimentation. Trans. Faraday Society $1952 ; \quad 48: 166-176$.

12. Talmage W, Fitch E. Determining thickener unit areas. Industrial \& Engineering Chemistry 1955; 47; $38-41$.

13. Yoshioka N, Hotta Y, Tanaka S, et al. Continuous thickening of homogeneous flocculated slurries, Chemical Engineering1957; 21: 66-74.

14. Wilhelm J, Naide Y. Sizing and operating continuous thickeners. Mining Engineering 1981; 33: 1710-1718.

15. Dahlstrom D, Fitch E. Mineral Processing Handbook. New York 1985

16. Yalcin T. Thickening. Bulletin of the Canadian Institute of Metallurgy 1988; 81: 910.

17. Kelly EG, Spottiswood DJ. Introduction to mineral processing. Wiley New York 1982

18. Buscall R, White LR. The consolidation of concentrated suspensions. Part 1 . The theory of sedimentation. Journal of the Chemical Society, Faraday Transactions 1: Physical Chemistry in Condensed Phases 1987; 83: 873-891.

19. Landman K, White L, Buscall R. The continuous flow gravity thickener: Steady state behavior. AIChE journal 1988; 34: 239-52.

20. Green MD. Characterisation of suspensions in settling and compression. Australia University of Melbourne 1997.

21. Garrido P, Concha F, Burger R. Settling velocities of particulate systems: 14. Unified model of sedimentation, centrifugation and filtration of flocculated suspensions. International Journal of Mineral Processing 72: 57-74.

22. De KRG, Boger D, Scales PJ. Compressive rheology: an overview. Rheology Reviews 2003; 125-66.

23. Garrido P, Burger R, Concha F, Burger R. Software for the design and simulation of gravity thickeners. Minerals 
engineering 2003;16: 85-92.

24. Usher SP, Scales PJ. Steady state thickener modelling from the compressive yield stress and hindered settling function. Chemical Engineering Journal 2005; 111: 253-261.

25. Gladman BR. The effect of shear on dewatering of flocculated suspensions. Australia University of Melbourne 2005.

26. Gladman BR, Rudman M, Scales PJ. Experimental validation of a 1-D continuous thickening model using a pilot column. Chemical Engineering Science 2010; 65: 3937-3946.

27. Zhang Y, Martin A, Grassia P. Prediction of thickener performance with aggregate densification. Chemical Engineering Science 2013; 101: 346-358.

28. Zhang Y, Martin A, Grassia P. Mathematical modelling of time-dependent densified thickeners. Chemical Engineering Science 2013; 99: 103-112.

29. Unesi M, Noaparast M, Shafaei SZ, et al. THE ROLE OF ORE PROPERTIES IN THICKENING PROCESS. PHYSICOCHEMICAL PROBLEMS OF MINERAL PROCESSING 2014; 50: 783-794.

30. Unesi M, Noaparast M, Shafaei SZ, et al. Modeling the effects of ore properties on water recovery in the thickening process. International Journal of Minerals, Metallurgy, and Materials 2014; 21: 851-861.

31. Ramin E, Flores-Aslina X, Sin G, et al. Influence of selecting secondary settling tank sub-models on the calibration of WWTP models-A global sensitivity analysis using BSM2. Chemical Engineering Journal 2014; 241: 28-34.

32. Betancourt F, Concha F, Sbarbaro D. Simple mass balance controllers for continuous sedimentation. Computers \& Chemical Engineering 2013; 54: 34-43.

33. Diehl S, Faras S. Control of an ideal activated sludge process in wastewater treatment via an ODE-PDE model. Journal of Process Control 2013; 23: 359-381.

34. Green DW, Perry RH. Perrys chemical engineers handbook, 8th edition, New York 2008.

35. Turner JPS, Glasser D. Continuous thickening in a pilot plant. Industrial \& Engineering Chemistry Fundamentals 1976;15(1): 23-30.

36. Gupta A. \& Yan, DS. Introduction to Mineral Processing Design and Operation, Perth, Australia 2006. 